\title{
TABLE OF CONTENTS
}

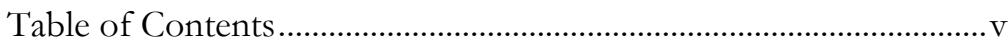

Acknowledgments ...........................................................................

Abbreviations ....................................................................................

Editions and translations of primary sources............................. xii

Chapter One. Introduction ............................................................... 1

Albrecht Dihle ...........................................................................

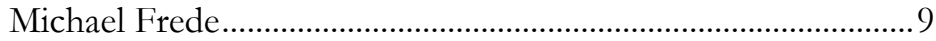

Charles Kahn and Richard Sorabji.............................................13

Chapter Two. The Hellenistic background ………………………......21

Why you should not believe in determinism: Epicurus

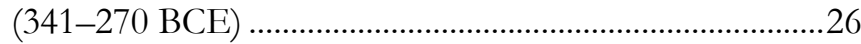

Why you should believe in determinism: the Stoics .................37

Chapter Three. A monistic theodicy: the biblical platonism of

Philo of Alexandria (25 BCE - 50 CE) …………………..........47

Philo on the Telos …………………………………....................49

Philo's mystical-theological understanding of the good...........51

Philo's defense of providence .......................................................57

Philo and Chrysippus on theodicy ..............................................62

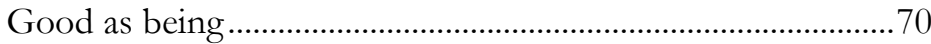

Philo on creation of man............................................................

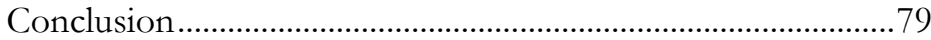

Chapter Four. A dualistic theodicy: the middle-platonism of

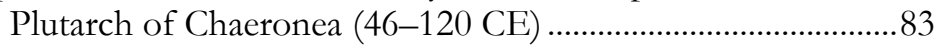

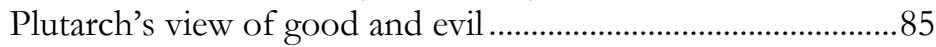

Problems of theodicy ………………………………….................93

Plutarch's cosmological solution to theodicy ...............................98

Providence and fate.................................................................102

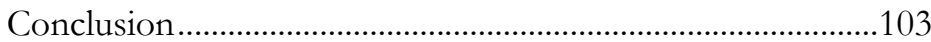

Chapter Five. Alexander's precedents ..............................................107

Alexander on responsibility and freedom...............................108 
Aristotle's ambiguity on determinism .......................................113

Peripatetic developments ..........................................................119

Middle-platonic developments ..................................................121

Chapter Six. Analysis of the De Fato..................................................127

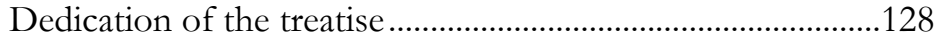

Structure of the treatise ..........................................................130

Deliberation's function toward moral progress.......................132

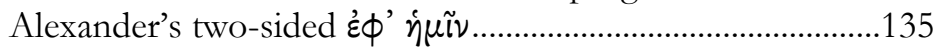

Fate, necessity, contingency ………………………...................137

The chain of necessary causes ....................................................138

The existence of the contingent ................................................139

Psychological evidence against the chain of fate .....................144

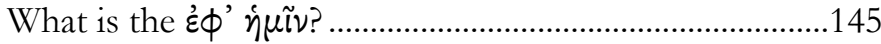

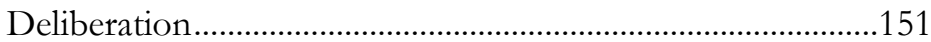

Aristotle on deliberation and responsibility ……………..........153

Chapter Seven. Indeterminist deliberation ..........................................157

Deliberation's advantage for moral progress ...........................181

The coherence of Alexander's rhetorical strategy …................185

Chapter Eight. Clement's rhetorical strategy ………........................187

Christianity as source of all knowledge......................................191

The object of knowledge...........................................................200

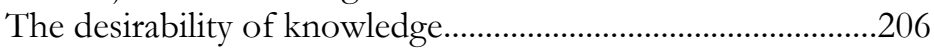

The structure of knowledge .......................................................209

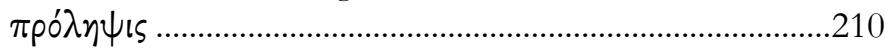

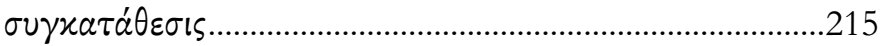

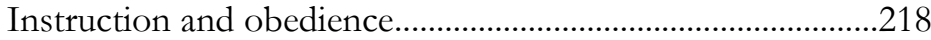

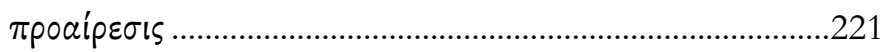

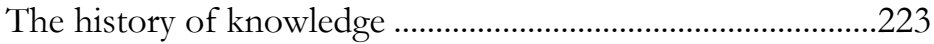

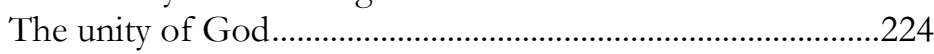

Historical progression of knowledge..........................................228

Chapter Nine. Clement's philosophical arguments.........................231

Clement's perspective on Gnostic ethical cosmology ...........232

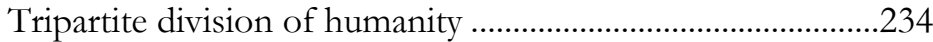

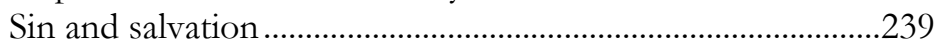

Clement's criticisms of this teaching .......................................249

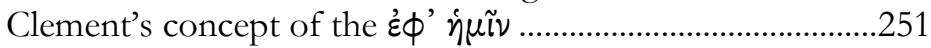

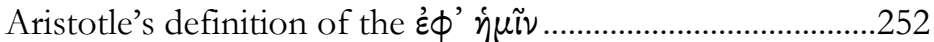

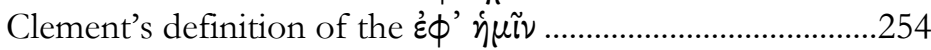




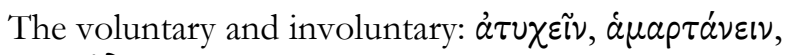
$a \dot{\delta}(x \varepsilon \tilde{\imath} \nu$ .255

Clement's appropriation of Aristotle..........................................262

Faith not predetermined by antecedent causes........................270

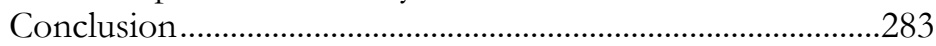

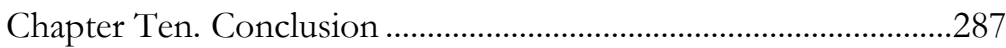

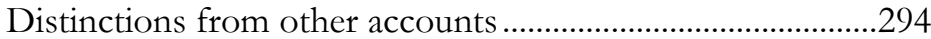

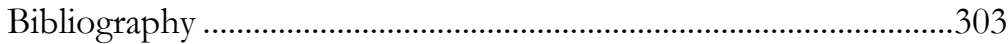

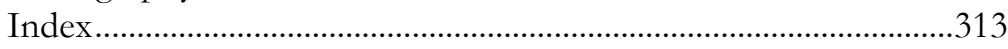


